\title{
Introducing students to patient safety through an online interprofessional course
}

This article was published in the following Dove Press journal:

Advances in Medical Education and Practice

7 December 2010

Number of times this article has been viewed

\author{
Amy V Blue ${ }^{1, *}$ \\ Laurine Charles ${ }^{2}$ \\ David Howell' \\ Yiannis Koutalos ${ }^{3}$ \\ Maralynne Mitcham ${ }^{4}$ \\ Jean $\mathrm{Nappi}^{5}$ \\ James Zoller ${ }^{6}$ \\ 'Office of the Provost, Medical \\ University of South Carolina, \\ Charleston, SC, USA; ${ }^{2}$ College \\ of Health Professions, Medical \\ University of South Carolina, \\ Charleston, SC, USA; ${ }^{3}$ Departments \\ of Ophthalmology and Neurosciences, \\ Medical University of South Carolina, \\ Charleston, SC, USA; ${ }^{4}$ Department of \\ Health Professions, Medical University \\ of South Carolina, Charleston, SC, \\ USA; ${ }^{5}$ South Carolina College of \\ Pharmacy, Medical University of \\ South Carolina, Charleston, SC, USA; \\ ${ }^{6}$ Department of Health Sciences and \\ Research, Medical University of South \\ Carolina, Charleston, SC, USA \\ *Authorship is listed alphabetically
}

Correspondence: Amy V Blue

Harper Student Center,

Medical University of South Carolina,

45 Courtenay Drive, MSC 175,

Charleston, SC 29425, USA

$\mathrm{Tel}+\mathrm{I} 8437923409$

Fax + I 843792 I506

Email blueav@musc.edu
Abstract: Interprofessional education (IPE) is increasingly called upon to improve health care systems and patient safety. Our institution is engaged in a campus-wide IPE initiative. As a component of this initiative, a required online interprofessional patient-safety-focused course for a large group (300) of first-year medical, dental, and nursing students was developed and implemented. We describe our efforts with developing the course, including the use of constructivist and adult learning theories and IPE competencies to structure students' learning in a meaningful fashion. The course was conducted online to address obstacles of academic calendars and provide flexibility for faculty participation. Students worked in small groups online with a faculty facilitator. Thematic modules were created with associated objectives, online learning materials, and assignments. Students posted completed assignments online and responded to group members' assignments for purposes of group discussion. Students worked in interprofessional groups on a project requiring them to complete a root cause analysis and develop recommendations based on a fictional sentinel event case. Through project work, students applied concepts learned in the course related to improving patient safety and demonstrated interprofessional collaboration skills. Projects were presented during a final in-class session. Student course evaluation results suggest that learning objectives and content goals were achieved. Faculty course evaluation results indicate that the course was perceived to be a worthwhile learning experience for students. We offer the following recommendations to others interested in developing an in-depth interprofessional learning experience for a large group of learners: 1) consider a hybrid format (inclusion of some face-to-face sessions), 2) address IPE and broader curricular needs, 3 ) create interactive opportunities for shared learning and working together, 4) provide support to faculty facilitators, and 5) recognize your learners' educational level. The course has expanded to include students from additional programs for the current academic year.

Keywords: patient safety, interprofessional, online education

Interprofessional education (IPE) is recognized as a means to improve health profession training and prepare practitioners to provide effective patient-centered collaborative care. ${ }^{1,2}$ Substantive focus on IPE has a longer history in the United Kingdom and Canada than in the United States. ${ }^{3-5}$ The role of interprofessional collaborative practice to improve patient safety was first identified in the 1999 Institute of Medicine To Err is Human report, ${ }^{1}$ and patient safety is an important focus of IPE. ${ }^{6}$ Since then, the presence of IPE in US medical schools and health profession education appears to be increasing in scope. ${ }^{7,8}$ Consistent with scholarly consensus, we refer to IPE as a situation in which "two or more professions learn with, from and about each other to improve collaboration and the quality of health care". ${ }^{9}$ 
Online learning provides an effective venue for health profession education, and ever more so for IPE, as it offers flexibility for scheduling and location of learning, as well as the potential to personalize instruction to individual needs..$^{10}$ With the challenges of scheduling, timetabling, and geographical distribution, online learning activities have been identified as a valuable approach for interprofessional learning. ${ }^{11-14}$ Casimiro et al ${ }^{15}$ and Luke et a ${ }^{16}$ present theoretical frameworks for online IPE, suggesting that a constructivist approach to learning in the online environment promotes reflection and critical thinking for learners. Through participation in online discussions, problem-solving exercises, and peer review, learners can create meaning from experiences through their interactions with other learners and with their learning environment.

In this paper we describe our efforts in implementing an online interprofessional patient-safety-focused course required for a large group (300) of first-year health profession students. We discuss institutional context, course development and design, course description, instructional features, and evaluation results from students and faculty facilitators, and conclude with recommendations for others interested in developing interprofessional online courses for students. We build upon the descriptions of other online IPE activities for students ${ }^{11-14}$ and address issues associated with providing a required experience for a large group of students on an academic health campus, in contrast to providing elective learning activities. ${ }^{12-14}$

\section{Institutional context}

The Medical University of South Carolina (MUSC) (Charleston, SC, USA) is a free-standing academic health center composed of six colleges: dental medicine, graduate biomedical sciences, health professions, medicine, nursing, and pharmacy. The total annual enrollment is approximately 2500 students. Since the 1990s, the institution has engaged in a variety of interdisciplinary and interprofessional initiatives, with early work focused on quality improvement through interdisciplinary collaboration. ${ }^{17,18}$ More recent efforts (since 2000) have included several co-curricular, elective experiences for students: 1) the Presidential Scholars Program, ${ }^{19}$ a year-long program for selected students to learn more about the complexities of the health care system and interprofessional teamwork; 2) a CLARION interprofessional case competition for students, modeled after the original established in Minnesota; ${ }^{20}$ and 3) a student-run interprofessional clinic for local uninsured individuals, the CARES clinic. ${ }^{21}$ Additionally, some students during required clinical rotations have participated in the Interprofessional Service Learning Project. ${ }^{22}$

As an institution accredited by the Southern Association of Colleges and Schools, MUSC is required to implement a 10-year student-focused quality enhancement plan for reaffirmation of accreditation..$^{23}$ In 2007, the institution adopted an IPE initiative, Creating Collaborative Care (C3). $\mathrm{C} 3$ is designed around a conceptual framework informed by transformative learning theory ${ }^{24,25}$ and rooted in general adult learning theories. ${ }^{26-28}$ It has an operational infrastructure and the following four major goals for student achievement, as described by Blue et al: ${ }^{29}$

Goal 1: Students will acquire teamwork competencies.

Goal 2: Students will acquire knowledge, including the values and beliefs, of health professions different from their own discipline that will enable them to define interprofessional health care delivery or research.

Goal 3: Students will apply their teamwork competencies in a collaborative interprofessional health care delivery or research learning setting.

Goal 4: Students will demonstrate their teamwork competencies in collaborative interprofessional health care delivery or translational research contexts.

Several key events led to the development of the online IPE patient-safety-focused course. The C3 Curricular Domain, described in detail by Blue et $\mathrm{a}^{29}$ initiated internal discussions about approaches to introduce a required substantive introductory IPE experience for students that would address Goal 2 and Goal 3. We have held an Interprofessional Day (IP Day) for all first-year students from all colleges at MUSC since 2006. In 2007, it expanded to include secondyear students as well. IP Day events include a keynote presentation for all participants followed by small group breakout sessions where a faculty member and a student, each from different colleges, facilitate interprofessional case discussions designed for students to learn more about each others' professions. We recognized that a single event was insufficient for in-depth interprofessional learning, and consequently we wanted to build upon students' IP Day experiences to create a more meaningful introductory IPE learning context. According to our $\mathrm{C} 3$ conceptual framework, students would engage in more advanced interprofessional experiences later in their training to further build upon and demonstrate their IPE knowledge and skills previously acquired.

\section{Course development and design}

We recognized that the course would need to include content of value beyond interprofessional competencies for academic 
programs to be eager to incorporate it as a requirement in their curricula. To identify curricular content needs, two leaders from the C3 Curricular Domain interviewed academic deans from all colleges to identify specific areas of content that could be taught interprofessionally and provide relief for current course loads. Following these interviews, an interprofessional course design subcommittee was formed from the C3 Curricular Domain to develop a required IPE course for first-year students. The decision to offer the course for first-year students had important ramifications for the content of the course, as discussed in our recommendations below.

The decision to conduct the course primarily online addressed important obstacles of academic calendars and scheduling. An online format also offered flexibility for faculty participation; facilitation of students' online learning could fit around faculty members' busy schedules. To ensure an interprofessional teamwork experience, students would work together in interprofessional teams on a course project during nonscheduled class time. A final in-class session was scheduled for students to present their project work to other classmates and the faculty facilitator.

To promote students' interprofessional learning, we grounded course design in constructivist theories and IPE competencies described in the literature. ${ }^{15,30}$ We followed the learning sequence from the $\mathrm{C} 3$ conceptual framework (a spiral of acquisition-application-demonstration) to guide the development of specific learning activities within each content module (Table 1). We wanted to ensure that students learned with, from, and about each other to improve health care. The promotion of reflection and critical thinking, the use of real-world problems to apply acquired knowledge, the need for interprofessional teamwork, and learning about each others' professional perspectives were fundamental design elements and manageable in an online format.

We decided to model the CLARION competition method $^{20}$ of an interprofessional case discussion of a fictional sentinel event for the group project. Creating a fictional sentinel event from scratch allowed the course design subcommittee to include specific teaching points relating to the course objectives and to address the course's overall theme of patient safety. The case centers on a Mexican immigrant female who, following a tooth extraction and a series of medical errors in treating the infection that subsequently developed, experienced an ischemic stroke with brain injury. The case permitted the inclusion of elements that would appeal to students of different professions so all students would see their role within health care and others could learn about that role. The course design subcommittee consulted with the MUSC Hospital's Director of Outcomes and Quality Management and gained assurance that the case represented real-life scenarios involving medical errors.

Once the course was designed, leaders of the C3 Curricular Domain re-engaged the academic deans to inform them about the course objectives, content, and learning activities. We sought their feedback prior to bringing the request to the college deans for approval of the course as a requirement for their students. The college deans endorsed the course concept; once the final syllabus and case were developed, these were provided to them as information.

The course was first piloted as an elective in the fall of 2009 , enrolling 35 students facilitated by nine faculty facilitators. The university uses Blackboard as its current learning management system, and thus we used it for the course's online platform. The design committee communicated

Table I Course design, learning activities, and online format context for the interprofessional patient safety course

\begin{tabular}{|c|c|c|}
\hline Stage of learning & Learning activities & Online format \\
\hline Acquisition & $\begin{array}{l}\text { Learning new content information through } \\
\text { reading and viewing for each of } 4 \text { modules: } \\
\text { I. The Health Care System and Calls for Improvement } \\
\text { 2. Negotiating Across Cultures } \\
\text { 3. Social Determinants of Health } \\
\text { 4. Evidence-based Decision-making in Practice and Research }\end{array}$ & $\begin{array}{l}\text { Posting of select articles, videos, and other } \\
\text { resources for each module }\end{array}$ \\
\hline Application & $\begin{array}{l}\text { Reflecting and proposing solutions to each phase } \\
\text { of the fictional sentinel case event. For example: } \\
\text { Module I: how would the patient fare in a different } \\
\text { health system in terms of access to care and affordability? } \\
\text { Module 2: (I) how does the patient's culture influence } \\
\text { her health behaviors? How are your beliefs different } \\
\text { from hers and how would this impact your care for her? }\end{array}$ & $\begin{array}{l}\text { Postings on discussion board and } \\
\text { responses by student team members and } \\
\text { faculty facilitator }\end{array}$ \\
\hline Demonstration & $\begin{array}{l}\text { Working in an IP team and conducting a root } \\
\text { cause analysis of a sentinel event in a fictional case }\end{array}$ & $\begin{array}{l}\text { Student IP team presentation of results of } \\
\text { root cause analysis to one other IP team }\end{array}$ \\
\hline
\end{tabular}

Abbreviation: IP, interprofessional. 
regularly with the university's education technology faculty to identify and resolve Web and other technology-related issues to facilitate the online learning environment. Faculty facilitators and program staff solicited ongoing feedback from students to troubleshoot and problem-solve as needed. Suggestions from students for course improvement included developing a timeline for progress toward completion of group projects and posting live links in the course room for required reading. Based on these and faculty facilitator feedback, the course design subcommittee made minor modifications prior to official course implementation.

\section{Course description}

The Transforming Health Care for the Future (IP 710) course was introduced as a required course for 300 first-year dental, medical, and Bachelor of Science Nursing (BSN) students at MUSC in spring 2010. Ten students from the Colleges of Pharmacy and Health Professions enrolled on an elective basis, as their programs were not introducing the course into their required curricula at the time. The purpose of the course is to lay the foundation for beginning (first-year) health profession students to understand the complexities of the health care system and the role of interprofessional collaboration to improve patient safety in the system. The course addresses objectives and content areas of common need across the six colleges. The course objectives are as follows:

- Demonstrate basic teamwork skills in an interprofessional learning environment.

- Define the role of health professions and identify opportunities to seek the expertise of health professions different from their own for improving health care delivery and research.

- Identify ways in which interprofessional collaboration methods can improve health care delivery systems through attention to: 1) patient safety and error reduction; 2 ) the intersection of ethics, culture, and biomedicine; 3) health care disparities; 4) social determinants (ie, income, education, employment, social status, etc); and 5) evidence-based decision-making.

The course content addresses several areas: 1) team skills and communication skills, 2) interprofessional collaboration, 3) health care system components, 4) patient safety and medical error reduction, 5) cultural competency in health care, 6) ethical issues in health care, 7) healthcare disparities, 8) social determinants of health, and 9) evidence-based decision-making.

Students worked online in groups of five with a faculty facilitator; facilitators were responsible for two student groups. Four thematic modules were created for the course with associated objectives, online learning materials of videos, faculty-created PowerPoint presentations, readings, and assignments. All learning materials were placed on Blackboard for students to access. Students were required to complete assignments for each module, post them online, and respond to group members' assignments for purposes of group discussion. The "Group Discussion Board" feature was used for threaded discussions in the Blackboard system. As described above, a fictional sentinel event case served as a vehicle for learning course content through module assignments and project completion. Students worked in interprofessional teams to complete the project. The project required them to conduct a root cause analysis of the sentinel event and determine recommendations and a plan to improve identified systems issues in the fictional health care setting. The project was presented to their facilitators on the last class day. Students' performance in the course was graded pass/fail, with students required to complete assignments and responses in a timely manner and participate in project work. A self and team member assessment of the group's effort was conducted at the end of the course, and faculty facilitators graded the projects. Table 1 presents how we applied the course design principles to specific learning activities within the online format.

\section{Course evaluation results Methods}

Students were asked to complete a paper-and-pencil endof-course evaluation form at the last class session. Items addressed broad and specific course learning goals, including course content areas, and responses were on a scale of 1 (strongly disagree) to 5 (strongly agree). Items addressing broad course goals asked whether through the course the students' 1) appreciation of interprofessional collaboration increased, 2) knowledge about specific professions increased, 3) knowledge about their own profession's role in interprofessional teamwork increased, and 4) teamwork skills improved. Students were also asked whether 1) the activity was worthwhile for their professional development, 2) they enjoyed learning with students from other professions, and 3) they would like more face-to-face time with their group. To assess students' perceptions of their knowledge gain in the course content areas, students were asked whether their knowledge in the following areas improved due to course content: 1) the health care system, 2) cultural competency, 3) patient safety/ error reduction, 4) ethics, 5) social determinants of health, 6) health disparities, and 7) evidence-based decision-making. Students were also asked to indicate the strengths of the course and areas for improvement. 
In addition to surveying students about their experience in the course, we surveyed faculty facilitators to learn their perspectives about students' learning in the course. Several items paralleled the items asked of students, in order to gain the perspectives of both groups on similar issues. Questions asked whether the facilitator thought that through the course the students' 1) appreciation of interprofessional collaboration increased, 2) knowledge about specific professions increased, 3) knowledge about their own profession's role in interprofessional teamwork increased, and 4) teamwork skills improved. Additionally, facilitators were asked whether 1) the activity was worthwhile for students' development, 2) they would like more face-to-face time with students in the course, and 3) their workload as a faculty facilitator was manageable. Responses were on a 1 (strongly disagree) to 5 (strongly agree) scale.

The closed-ended items on the student and faculty evaluations were analyzed using descriptive statistics. The percentage agreement was the metric used for reporting results. The open-ended items about perceived strengths and areas for improvement on the students' evaluation were content analyzed for major themes to determine areas for improvement for the next course offering.

\section{Results}

A total of 267 (91\%) students completed the course evaluation. Table 2 presents the percentage agreement about the course general learning goals. The majority of respondents indicated that their appreciation for interprofessional collaboration increased through the course, as well as their knowledge of specific professions and the role of their own professions in interprofessional teamwork. Slightly over $50 \%$ responded that their teamwork skills increased. Less than half the students responded they thought the course was worthwhile for

Table 2 Percentage agreement of students to course evaluation items related to broad learning goals and course format

\begin{tabular}{llll}
\hline Item & Disagree & Neutral & Agree \\
\hline $\begin{array}{l}\text { Appreciation for IP collaboration } \\
\text { increased }\end{array}$ & 6.1 & 15.9 & 78.0 \\
$\begin{array}{l}\text { Knowledge of specific } \\
\text { professions increased }\end{array}$ & 12.7 & 18.0 & 69.4 \\
$\begin{array}{l}\text { Knowledge about my profession's } \\
\text { role in IP work increased }\end{array}$ & 12.6 & 26.5 & 60.8 \\
$\begin{array}{l}\text { Teamwork skills improved } \\
\begin{array}{l}\text { This activity was worthwhile } \\
\text { for my professional development }\end{array}\end{array}$ & 12.8 & 35.3 & 51.9 \\
$\begin{array}{l}\text { I enjoyed learning with students } \\
\text { from other professions }\end{array}$ & 4.9 & 32.8 & 40.2 \\
$\begin{array}{l}\text { I would like more face-to-face } \\
\text { time with my group }\end{array}$ & 16.0 & 15.3 & 79.7 \\
\hline
\end{tabular}

Abbreviation: IP, interprofessional. their professional development. Eighty percent of students indicated they enjoyed learning with students from other professions in the course. Fifty-nine percent stated that they would have liked more face-to-face time with their classmates. When asked about specific course content areas, the majority of respondents indicated that their knowledge increased in all content areas. The highest percentage of respondents indicated that their knowledge of patient safety increased through the course; the lowest percentage of responses was associated with evidence-based medicine. Table 3 presents the percentage agreement about specific course content areas.

The most common suggestion for improvement was more face-to-face time. Example comments are: "Have groups meet early on - name to face", "Have more face-toface time with the groups", and "Scheduled time meetings of the group". Another common suggestion was to increase the variety of case scenarios for discussion rather than relying on the one patient case. Example comments about this suggestion are: "Have different scenarios", "Maybe add an extra case for the discussions; the case became kind of redundant", and "More cases - not just one".

Overwhelmingly, the greatest strength of the course stated by students was the opportunity to interact with students from other professions: "Meeting students from other colleges at MUSC", "It was good to meet people outside the college of medicine", and "I enjoyed getting to know other students from different colleges".

Eighty-six percent of the small-group facilitators returned the evaluations. Overall, the majority of facilitators agreed that the course increased students' appreciation of interprofessional collaboration, their knowledge of specific professions, their knowledge about their profession's role in interprofessional work, and their teams skills. Over $90 \%$ agreed that the course was worthwhile for the students' professional development, and $80 \%$ agreed that the workload as faculty facilitator was manageable. Table 4 presents the results of the faculty facilitator evaluations.

Results from student course evaluations and faculty facilitator course evaluations suggest that the interprofessional

Table 3 Percentage agreement of students to course evaluation items related to course content areas

\begin{tabular}{llll}
\hline Item & Disagree & Neutral & Agree \\
\hline Health care system & 10.3 & 22.1 & 67.6 \\
Cultural competency & 9.4 & 18.4 & 72.3 \\
Patient safety & 6.5 & 15.5 & 78.0 \\
Ethics & 9.8 & 26.5 & 63.7 \\
Social determinants of health & 5.7 & 21.3 & 73.0 \\
Health disparities & 8.5 & 21.6 & 69.8 \\
Evidence-based decision-making & 18.0 & 29.8 & 52.3 \\
\hline
\end{tabular}


Table 4 Percentage agreement of faculty facilitators with course evaluation items

\begin{tabular}{llll}
\hline Item & Disagree & Neutral & Agree \\
\hline $\begin{array}{l}\text { Through this course I think students': } \\
\quad \begin{array}{l}\text { Appreciation of interprofessional } \\
\text { collaboration increased. }\end{array}\end{array}$ & 3.3 & 0.0 & 96.7 \\
$\quad \begin{array}{l}\text { Knowledge about specific } \\
\text { professions increased. }\end{array}$ & 6.6 & 16.7 & 76.7 \\
$\quad \begin{array}{l}\text { Knowledge about their own } \\
\text { profession's role in }\end{array}$ & 3.3 & 6.7 & 90.0 \\
$\quad \begin{array}{l}\text { interprofessional work increased. } \\
\quad \text { Teamwork skills improved. }\end{array}$ & 3.3 & 6.7 & 90.0 \\
$\begin{array}{l}\text { This course was worthwhile for } \\
\text { students' professional development. }\end{array}$ & 3.3 & 3.3 & 93.4 \\
$\begin{array}{l}\text { I would like more face-to-face } \\
\text { time with students in the course. }\end{array}$ & 6.9 & 20.7 & 72.4 \\
$\begin{array}{l}\text { My workload as a faculty facilitator } \\
\text { was manageable. }\end{array}$ & 10.0 & 10.0 & 80.0 \\
\hline
\end{tabular}

learning and course content goals were achieved in the course. Of interest is that although the majority of students did not perceive the course as worthwhile for their professional development, the majority of them indicated agreement that their learning of course goals and content increased during their participation in the course. Because we did not use an examination, we do not have objective outcome measures to complement these assessments. Faculty facilitators held a contrasting perspective about the course's worthiness for students' professional development, with the majority of them indicating that it was worthwhile. We recognize that the faculty facilitators were self-selected, so they were more than likely to hold a positive view of the educational value of the course.

As stated previously, the course was graded pass/fail, with student evaluation components consisting of their completion of assignments and peer responses in a timely manner and participation in the group project. None of the group projects were deemed as poor and requiring revision. All students passed the course. Future work will examine the quality of students' assignments and projects to assess course effectiveness from this perspective.

\section{Recommendations}

\section{Consider a hybrid course format}

The use of online learning, as discussed previously, addresses challenges of scheduling and timetables. From the student perspective, online learning provides accessibility to course activities 24 hours per day and flexibility to complete tasks while balancing concomitant other course demands, co-curricular activities, and personal commitments. ${ }^{13,31}$ Many students indicated that they appreciated the flexibility of the online, asynchronous format provided. However, many students stated a preference for scheduled face-to-face meetings. We thought it would be easy for students to find a common time amongst themselves to meet for project work. However, this was challenging given different course schedules, including clinical responsibilities for the nursing students and the need to balance personal commitments. Additionally, we did not adequately consider the role of group socialization and identity and the benefits of an initial face-to-face meeting to accelerate the socialization process. ${ }^{11}$ It took students some time to familiarize themselves with each other in the online format. For the 2010-2011 course, groups meet in an introductory session and during two additional face-to-face meetings to briefly review module content and work on the group project. We recognize that for geographically dispersed programs, face-toface meetings are challenging. Some of our elective learners are on a remote campus. We are using video conferencing and Skype to connect for the face-to-face sessions.

One drawback to a strictly online format is that it results in asynchronous interaction and feedback, curtailing instructional back-and-forth discussion. Faculty at times wondered whether students read their responses to postings. The inclusion of a few face-to-face sessions is allowing faculty and students to review course content through face-to-face discussion.

\section{Address IPE and broader curricular needs}

Academic programs have multiple curricular needs to meet accreditation standards and provide current, quality, educational experiences for students. The addition of substantive new curricular content may be resisted because programs are complete with learning objectives and activities. Given our goal to add a new course into already full curricula, we sought to build a course to address programs' curricular needs. By doing this, we leveraged consent to add the course to programs' schedules beyond the argument that students needed an IPE experience. Programs have accommodated the course within their curricula in different manners. One modified course content to accommodate the IP 710 course within an existing course, some programs altered several courses to adjust for its inclusion in the overall academic program, and others accommodated it within the overall academic calendar so that the additional coursework during a semester would not be burdensome for students.

\section{Create interactive opportunities for shared learning and working together}

One of our goals was for students to apply their teamwork skills in the course through work on a real-world interprofessional team project. This provided cooperative learning, which is important 
in IPE. ${ }^{12,16,30}$ The project required shared problem-solving and decision-making, as well as exchange of professional perspectives about patient care issues. We built learning content and assignments with dual purposes. One purpose was for students to learn content that is common across the professions and apply it in a reflective manner to a patient case. The other purpose was to facilitate students' problem-solving for the project. The inclusion of patient cases, real-world problems, problem-solving experiences, personal and professional reflection, and opportunities to learn about professional roles is similar to what others report about effective online IPE. ${ }^{11-13,15,16}$ Our use of an interprofessional team project to reinforce effective interprofessional teamwork skills extended the online IPE experience beyond simply peer review of work posted online to actual collaborative learning.

\section{Provide support to faculty facilitators}

Small-group faculty facilitators are a critical component of the course. We recognize that members of our faculty are busy with multiple professional demands, and the addition of another course to teach adds to their responsibilities. All of our faculty facilitators volunteer to teach the course. To ease their workload, our course design committee created the course so the facilitator's role would be one of facilitation with students and not one of creating learning materials and activities. As members of our faculty are drawn from diverse professional backgrounds and none of the facilitators are necessarily content experts in all of the course subject areas, we wrote a teaching guide addressing the course module objectives and salient points from course resources. With this guide, a facilitator can reinforce key learning points in discussions and feedback with students. We also highlighted key points in the case used for the group project to assist facilitators in grading and providing feedback about the project. Cleak at el ${ }^{13}$ described similar support to faculty in their course. Other key course functions were supported centrally for facilitators, including support with the technology, scheduling of classrooms for the final class session, and communication about course requirements and details with all students.

\section{Recognize your learners' educational level}

The intentional choice to offer and require the course for firstyear students who had limited, if any, patient care experience was a significant constraint for our course development. Thus, it is important to explicitly recognize the educational level of the learners. One consideration to target first-year students was the desire for students to interact with each other interprofessionally before they had been molded by their distinct professional cultures. Another consideration was that students would be at approximately the same level of professional training (ie, prior to clinical rotations and substantive patient care experience) and therefore would, in general, have the same knowledge of clinical and health systems issues; that is, it would be a level playing field in terms of clinical knowledge. (One exception at our institution is our BSN students who begin clinical experience during their first semester).

Offering the course to first-year students, however, has had the drawback that these students have limited professional and clinical knowledge. This limits the educational material and the types of instruction. We recognized this and thereby minimized the amount of clinical information in the sentinel event case details because our learners may not have been exposed to such clinical knowledge yet. Thus, students were exposed to the course material (patient safety, cultural competency, social determinants of health, etc) in an abstract fashion, not directly in a patient care practice context. Although the sentinel event case provided a theoretical patient care/patient safety context in which students could apply course content and work interprofessionally, it was nonetheless an artificial setting. Some would criticize this artificiality as an important limitation for the course. However, we address such criticism by acknowledging the constraints of the students' educational level in the course, which then serves as a rationale for the particular course structure and scope.

\section{Future directions}

We find it important to continue evaluating and adjusting the course as it is offered to more students across the academic programs and feedback from students and faculty accumulates. We have already discussed some of the aspects of the course that were fairly straightforward to modify, such as adding more vignettes and examples and adding face-to-face meetings. A particularly important challenge is the development and implementation of objective measures of student learning, such as a written examination. This is an area in which we need further development and could involve following the students as they progress through their training and evaluating their interprofessional competence as they acquire professional expertise.

Keeping track of changes in the academic schedules and curricula of the colleges is important, as it might provide additional opportunities for further development of the course. Faculty support will also be critical, as the course involves a large number of faculty members to facilitate the numerous online small groups. It will be increasingly imperative to ensure that faculty members have the time to teach in the course and that resources come together to develop novel material for instruction. 


\section{Conclusion}

We have described our efforts at developing for a large group of first-year students an interprofessional online course with a patient safety emphasis. The course design was grounded in educational theories and IPE competencies and built within a larger institutional conceptual framework for IPE. Overall course evaluation results suggest that students acquired course content and achieved course goals, and faculty in the course were enthusiastic about students' learning. We offer several recommendations to others interested in advancing IPE at their own institution with the development of a course of this type.

\section{Disclosure}

The authors report no conflicts of interest in this work.

\section{References}

1. Committee on Quality Health Care in America, Institute of Medicine. Kohn LT, Corrigan J, Donaldson MS, editors. To Err is Human: Building a Safer Health System. Washington, DC: National Academy Press; 1999.

2. World Health Organization. Working Together for Health: The World Health Report 2006. Geneva: WHO; 2006.

3. Prevention Education Resource Center (PERC). Interprofessional education. Available from: http://www.teachprevention.org/interprofes sional.php. Accessed 2010 Feb 3.

4. Association of American Medical Colleges. The Mission, Vision, and Strategic Priorities of the AAMC. Washington, DC: Association of American Medical Colleges; 2007.

5. American Association of Colleges of Pharmacy. Annual Report of the Task Force on Interprofessional Education 2007-2008. Available from: http://www.aacp.org/governance/councilfaculties/Documents/ COF_InterprofessionalEducation 2008.pdf. Accessed 2010 Feb 3.

6. Reeves S. An overview of continuing interprofessional education. Contin Educ Health Prof. 2009;29(3):142-146.

7. Blue AV, Zoller J, Stratton TD, Elam CL, Gilbert J. Interprofessional education in US medical schools. J Interprof Care. 2010;24(2):204-206.

8. Lyons KJ, Giordano C. Special issue on interprofessional education and care. J Allied Health. 2010;39(3 Pt 2):192-193.

9. Center for the Advancement of Interprofessional Education. http:// www.caipe.org.uk/about-us/defining-ipe/. Accessed 2010 Feb 3.

10. Cook DA, Levinson AJ, Garside S, Dupras DM, Erwin PJ, Montori VM. Instructional design variations in internet-based learning for health professions education: a systematic review and meta-analysis. Acad Med. 2010;85:909-922.

11. Hughes M, Venture S, Dando M. On-line interprofessional learning: introducing constructivism through enquiry-based learning and peer review. J Interprof Care. 2004;18:263-268.

12. Solomon P, Baptiste S, Hall P, et al. Students' perceptions of interprofessional learning through facilitated online learning modules. Med Teach. 2010;32:e391-e398.
13. Cleak H, Williamson D, Lincoln G. Preparing health science students for interdisciplinary professional practice. J Allied Health. 2007; 36:141-149.

14. Varga-Atkins T, Cooper H. Developing e-learning for interprofessional education. J Telemed Telecare. 2005;11 (Suppl 1):102-104.

15. Casimiro L, MacDonald CJ, Thompson TL, Stodel EJ. Grounding theories of $\mathrm{W}(\mathrm{e})$ Learn: a framework for online interprofessional education. J Interprof Care. 2009;23:390-400.

16. Luke R, Solomon P, Baptiste S, et al. Online interprofessional health sciences education: from theory to practice. J Contin Educ Health Prof. 2009;29:161-167.

17. Chessman AW, Bellack JP, Lahoz MR, et al. Students add value to learning organizations: the Medical University of South Carolina experience. Qual Manag Health Care. 1998;6(2):38-43.

18. Greenberg RS, Bellack JP. Building an interdisciplinary culture. Medical University of South Carolina. In: Holmes D, Osterweis M, editors. Catalysts in Interdisciplinary Education. Washington, DC: Association of Academic Health Centers; 1999:59-78.

19. Ragucci KR, Steyer T, Wager KA, West VT, Zoller JS. The Presidential Scholars Program at the Medical University of South Carolina: an extracurricular approach to interprofessional education. $J$ Interprof Care. 2009;23(2):134-147.

20. Johnson AW, Potthoff SJ, Carranza L, Swenson HM, Platt CR, Rathbun JR. CLARION: a novel interprofessional approach to health care education. Acad Med. 2006;81(3):252-256.

21. Ellet JD, Campbell JA, Gonsalves WC. Patient satisfaction in a studentrun free medical clinic. Fam Med. 2010;42:16-18.

22. White A, Kern D, Blue A, et al. Creating Interprofessional Teams. Academic Exchange Quarterly. 2008;12(1):115-120.

23. Southern Association of Colleges and Schools. Principles of Accreditation: Foundations for Quality Enhancement. 2004. Available from: http://www.sacscoc.org/pdf/PrinciplesOfAccreditation.PDF. Accessed $2010 \mathrm{Feb} 4$

24. Mezirow J. Perspective transformation. Adult Education. 1978;28: 100-110.

25. Mezirow J, editor. Learning as Transformation: Critical Perspectives on a Theory in Progress. San Francisco: Jossey-Bass; 2000.

26. Kegan R. In Over Our Heads: The Mental Demands of Modern Life. Cambridge, MA: Harvard University Press; 1994.

27. Baxter-Magolda M. Creating Contexts for Learning and Selfauthorship: Constructive-Developmental Pedagogy. 1st ed. Nashville, TN: Vanderbilt University Press; 1999.

28. Baxter-Magolda M. Teaching to promote intellectual and personal maturity: incorporating students' worldviews and identities into the learning process. New Directions for Teaching and Learning, 82. San Francisco: Jossey-Bass; 2000.

29. Blue AV, Mitcham M, Smith T, Raymond J, Greenberg R. Changing the future of health professions: embedding interprofessional education within an academic health center. Acad Med. 2010;85(8):1290-1295.

30. Oandasan I, Reeves S. Key elements for interprofessional education. Part 1: the learner, the educator and the learning context. J Interprof Care. 2005;19 Suppl 1:21-38.

31. Miers ME, Clarke BA, Pollard KC, Rickaby CE, Thomas J, Turtle A. Online interprofessional learning: the student experience. $J$ Interprof Care. 2007;21:529-542.
Advances in Medical Education and Practice

\section{Publish your work in this journal}

Advances in Medical Education and Practice is an international, peerreviewed, open access journal that aims to present and publish research on Medical Education covering medical, dental, nursing and allied healthcare professional education. The journal covers undergraduate education, postgraduate training and continuing medical education

\section{Dovepress}

including emerging trends and innovative models linking education, research, and healthcare services. The manuscript management system is completely online and includes a very quick and fair peer-review system. Visit http://www.dovepress.com/testimonials.php to read real quotes from published authors. 